\title{
INVESTIGACIÓN
}

Recibido: 06/03/2019 --- Aceptado: 29/04/2019 --- Publicado: 15/03/2020

\section{DE LA CRÓNICA AL PERIODISMO, FUENTES PARA EL CONSTRUCTO DE LA SEMANA SANTA ILUSTRADA}

\author{
From the chronicle to journalism, sources for the construction \\ of the illustrated holy week
}

Rubén Sánchez Guzmán¹. Ayuntamiento de Madrid, Distrito Latina. España. Ruben_sanguzman@hotmail.com

Antonio Rafael Fernández Paradas. Universidad de Granada. España. Antonioparadas@ugr.es

\section{RESUMEN}

En el presente trabajo se pretende dar una visión de las celebraciones de la Semana Santa de Valladolid, y de sus celebrados conjuntos procesionales. No se pretende dar una simple visión histórica de esta celebración en el siglo XVIII, si no trazar que pensaban los contemporáneos de ese siglo de este potencial, cultural, artístico y antropológico que suponía la celebración a través de sus escritos. Es de destacar que tan singular fenómeno no se ciñó a las fronteras de la ciudad sino que fue un tema en consideración para la historiografía de ámbito nacional, por lo que recogemos tanto fuentes locales como nacionales, en un siglo el XVIII, que pasaremos de una mentalidad tardo barroca a una plenamente ilustrada, cambio que en ocasiones se desarrolló de manera traumática, pensamientos encontrados que quedaron marcados en maneras distintas de narrar, desde la historia pre científica hasta la crónica periodística. De manera específica se han analizado y comparado tres fuentes de información coetáneas a la época, una de ellas el primer diario publicado en Valladolid. Las fuentes utilizada son las siguientes: El Diario de Valladolid fue redactado por Ventura Pérez entre 1720 y 1784; la Historia Secular y Eclesiástica de la muy Antigua, Augusta, Coronada, muy Ilustre, muy Noble, Rica y muy Leal Ciudad de Valladolid, escrita por Manuel Canesi Acevedo (1681-1750) y el Diario Pinciano, primer periódico de Valladolid, obra de José Mariano Beristáin, cuyo primer número se editó el 7 de febrero de 1787, siendo el primer periódico de Valladolid. Se ha realizado un vaciado de estas fuentes, cuya base es la justificación documental del presente trabajo.

\footnotetext{
${ }^{1}$ Rubén Sánchez Guzmán: licenciado en Historia del Arte por la Universidad Autónoma de Madrid. En la actualidad ejerce como profesor de Historia del Arte y Conocer Madrid, en los Centros Culturales del Ayuntamiento de Madrid.
} 
PALABRAS CLAVE: Valladolid - Semana Santa - siglo XVIII - pasos - procesiones Escultura - Diario de Valladolid.

\begin{abstract}
In the present study we intend to offer a general understanding about the Holy Week (Easter) in Valladolid and its famous processional ensembles with different sources. We are not offering a simple historic view on this celebration in the 18th century, but showing what the people in those days thought about the celebration (and its cultural, artistic and anthropological importance) as is reflected in their writing. The Holy Week in Valladolid was an important theme in historiography on a national level, hence we gather here both local and national sources from a time in which people went from a late Baroque mentality to a fully Enlightened (Age of Enlightenment) one. This change was sometimes traumatic, and these conflicting thoughts can be appreciated in the different ways of narrating, from pre-scientific history to journalistic chronicle. Specifically, three sources of information have been analyzed and compared to the time, one of them the first newspaper published in Valladolid. The sources used are the following: El Diario de Valladolid was written by Ventura Pérez between 1720 and 1784; the Secular and Ecclesiastical History of the very Ancient, Augusta, Coronada, very Illustrious, very Noble, Rich and Very Loyal City of Valladolid, written by Manuel Canesi Acevedo (1681-1750) and the Diario Pinciano, first newspaper of Valladolid, work of José Mariano Beristáin, whose first issue was published on February 7, 1787, being the first newspaper of Valladolid. There has been a voiding of these sources, whose basis is the documentary justification of this work.
\end{abstract}

KEY WORDS: Valladolid - Holy Week - 18th Century - pasos - processionsSculpture- Diario de Valladolid.

\title{
DA CRÔNICA AO JORNALISMO, FONTES PARA A CONSTRUÇÃO DA SEMANA SANTA ILUSTRADA
}

\section{RESUME}

Neste presente trabalho pretende-se dar uma visão das celebrações da Semana Santa de Valladolid, e de seus celebrados conjuntos de procissão. Não se pretende dar uma simples visão histórica desta celebração no século XVIII, e sim traçar o que pensavam os contemporâneos de este século de este potencial, cultural, artístico e antropológico que supunha a celebração através de seus escritos. É de destacar que tão singular fenômeno não se cingiu às fronteiras desta cidade, se não que foi um tema em consideração para a historiografia de âmbito nacional, pelo qual recolhemos fontes de informação tanto locais como nacionais, em um século, o XVIII, que passaremos de uma mentalidade barroca tardia a uma plenamente ilustrada, mudança que em ocasiões se desenvolveu de maneira traumática, pensamentos encontrados que ficaram marcados em maneiras distintas de narrar, desde a história pré-científica até 
a crônica jornalística. De maneira especifica foram analisadas e comparadas três fontes de informação coetâneas à a época, uma delas o primeiro jornal publicado em Valladolid. As fontes utilizadas são as seguintes: El Diario de Valladolid foi redigido por Antigua, Augusta, Coronada, muy Ilustre, muy Noble, Rica y muy Leal Ciudad de Valladolid, escrita por Manuel Canesi Acevedo (1681-1750) e o Diario Pinciano, primeiro jornal de Valladolid, obra de José Mariano Beristáin, cujo primeiro número foi editado em 7 de fevereiro de 1787, sendo o primeiro jornal de Valladolid. Foi feito um esvaziamento destas fontes, cuja base é a justificação documental do presente trabalho.

PALAVRAS CHAVE: Valladolid - Semana Santa - século XVIII - procissões Escultura - Jornal de Valladolid.

\section{Como citar el artículo:}

Sánchez Guzmán, R. y Fernández Paradas, A. R. (2020). De la crónica al periodismo, fuentes para el constructo de la semana santa ilustrada. [From the chronicle to journalism, sources for the construction of the illustrated holy week].Vivat Academia. Revista de Comunicación, 150, 1-24. doi: http://doi.org/10.15178/va.2020.150.1-24 Recuperado de

http://www.vivatacademia.net/index.php/vivat/article/view/1170

\section{INTRODUCCIÓN}

El siglo XVIII, supuso un importante cambio a lo que la celebración de la Semana Santa refiere, pasamos de una sociedad barroca, que desarrollo el concepto de cofradía penitencial, amén de exaltación devocional a partir de la imagen procesional a otra ilustrada, que no entendió a no quiso entender lo anterior. Los nuevos planteamientos religiosos que abogaban con una religiosidad más pura, despojada de cualquier superstición, si bien no era la del pueblo, era la de las élites que tenían en poder. El propio concepto de fiesta barroca, con todo lo que implica, manifestaciones, culturales, paralitúrgicas y artísticas, fueron tenidas por manifestaciones en exceso populares que traslucían una religiosidad supersticiosa y heterodoxa. Las medidas que desde la cúpula del estado se dieron en aras de un purismo religioso, a la postre fueron el detonante de la profunda crisis que afectó a estas celebraciones desde finales del XVIII, hasta bien entrado el XIX. Como bien a trabajado Sánchez Herrero, más que una crisis, se debería de hablar de crisis distintas y sucesivas, así si el reinado de Carlos III, está marcado por una crisis institucional y reformista que llegaría hasta la guerra de la Independencia, las crisis del siglo XIX, marcadas por la desamortización de Mendizábal son de índole económica e ideológica, por la irrupción de la mentalidad liberal progresista (Sánchez Herrero, 2003, pp. 171-172)

\section{OBJETIVOS}

El objetivo de la presente publicación es analizar diversas fuentes de información como base para la construcción del conocimiento sobre la Semana Santa Vallisoletana en el siglo XVIII, en diversos aspectos, tales como la organización, desfiles, diputas, 
decadencia, conservación etc. La Semana Santa de Valladolid tuvo un extraordinario correlato literario en diferentes épocas, aportando cada etapa visiones propias en nuevos formatos. Tal es el caso de la prensa escrita, que vino a crear un espacio de divulgación terriblemente rico al estar lleno de afirmaciones en primera persona, lo que nos permite analizar las mentalidades de la época.

Utilizando estas fuentes se pretende construir la imagen mental que la propia sociedad vallisoletana al respecto de la que era una de sus manifestaciones sociales más importantes, la Semana Santa. De manera específica los objetivos propuestos son los siguientes:

1. Valorar la importancia de determinadas fuentes como elemento para la construcción del conocimiento histórico.

2. Analizar los medios de comunicación de la época como fuente de información para comprender las mentalidades de la época por medio de la Semana Santa.

3. Comparar y analizar tres fuentes de información del siglo XVIII relacionadas con la Semana Santa de Valladolid.

4. Analizar las influencias de las ideas ilustradas en la Semana Santa Barroca.

5. Evidenciar la propia organización de la Semana Santa de la época.

6. Ejemplificar las críticas y las medidas de conservación tomadas en la época sobre los pasos procesionales.

\section{METODOLOGÍA}

La metodología utilizada es de corte cualitativo y comparativo ya que se analizan los contenidos de diversos textos y publicaciones periódicas del siglo XVIII que versan sobre la Semana Santa de Valladolid, tratando cuestiones específicas como son los pasos, la conservación de éstos o la autoría de las imágenes. (Sanz, R., 2017). A su vez, se ha utilizado un método analítico, mediante en el cual se ha llevado a cabo una investigación enfocada en el análisis de cuestiones particulares que permiten ofrecer una visión holística del objeto de la investigación.

La metodología de la presente investigación se ha desarrollado a lo largo de cinco fases (Costas Fontán, N. 2015):

\section{Fase preliminar. Incluye:}

Delimitación del objeto de estudio. Aunque el texto presenta multitud de referencias a fuentes históricas literarias y artística de la época, la base del análisis ha partido de tres fuente principales: El Diario de Valladolid fue redactado por Ventura Pérez (Egido, 1983, pp. I-XIV) entre 1720 y 1784; la Historia Secular y Eclesiástica de la muy Antigua, Augusta, Coronada, muy Ilustre, muy Noble, Rica y muy Leal Ciudad de Valladolid, escrita por Manuel Canesi Acevedo (1681-1750) y el Diario Pinciano, primer periódico de Valladolid, obra de José Mariano Beristáin, cuyo primer número se editó el 7 de febrero de 1787, siendo el primer periódico de Valladolid. Se ha realizado un vaciado de estas fuentes, cuya base es la justificación documental del presente trabajo. 


\section{Fase exploratoria. Incluye:}

Durante esta etapa, hemos consultado obra de obras de referencias y publicaciones científicas especializadas en escultura, Semana Santa, conservación, etc. Esta fase del trabajo nos ha permitido contrastar las fuentes analizada como objeto de esta investigación. Se realizado una búsqueda de información bibliográfica especializada que nos ha permitido matizar, explicar o ilustrar las afirmaciones vertidas por las fuentes analizadas. Así por ejemplo en relación a la autoría de los pasos, las informaciones recogidas en las fuentes se han contrastado con investigaciones sobre el tema, lo que nos ha permitido valorar críticamente los comentarios primigenios.

3. Fase descriptiva. Incluye:

Se han analizado tres fuentes principales de referencia. Previo a la sistematización de las informaciones contenidas en las fuentes, se han tenido en cuenta las estructuras de las mismas y los modos de organización de la información. Se ha realizado un análisis descriptivo de las fuentes con carácter histórico.

4. Fase comparativa e interpretativa. Incluye:

En esta fase de la investigación se ha agrupado las informaciones vertidas en diversas categorías, como son número de pasos, sedes, organización de la procesión, conflictos, atribuciones, conservación de los pasos etc. En función de estas categorías se han comparado las fuentes objeto de estudio, enriqueciendo la investigación con otras fuentes primarias de la época y textos de investigadores contemporáneos.

5. Fase conclusiva. Incluye:

Para finalizar el trabajo, se proponen una serie de conclusiones que compilan los resultados obtenidos en el análisis.

\subsection{Las fuentes de referencia}

La Semana Santa de Valladolid y su manifestación artística clave, los pasos procesionales, no pasaron desapercibidos a escritores, teóricos y viajeros del siglo XVIII. Teóricos nacionales como Antonio Palomino, El Parnaso Español Pintoresco Laureado (1724), Antonio Ponz, Viaje de España (1788), Juan Agustín Ceán Bermúdez Diccionario Histórico de los más ilustres profesores de las Bellas Artes en España (1800) o Isidoro Bosarte, Viaje artístico a varios pueblos de España. Con el juicio de las obras de las nobles artes que en ellos existen y épocas a que pertenecen. Viaje a Segovia, Valladolid y Burgos (1804) y otros locales como Ventura Pérez, Manuel Canesi Acevedo o Mariano Beriatáin, se harán eco de ellos y nos darán referencias en sus obras. Si bien los tratadistas nacionales son de sobra conocidos, queremos destacar los autores de las fuentes manejadas vallisoletanas. 
El Diario de Valladolid fue redactado por Ventura Pérez (Egido, 1983, pp. I-XIV) entre 1720 y 1784 y completada con noticias recogidas de diversos autores anteriores al año 20, y otras posteriores al 84, añadidas por los herederos del propio autor. La valoración histórica de obra no se cifra solo en los datos históricos (comprobados en la mayoría de las ocasiones), sino en la ocasión que ofrece para captar a los "hombres que vivian y morían en aquellas casas y conventos y que andaban por la calle" (Egido, 1983, pp. III-IV). No pudo difundirse tanto como al autor le hubiera gustado, porque el analfabetismo era una barrera difícil de salvar, pero reflejo una sensibilidad peculiar, según Teófanes Egido "como por fortuna disponemos de un estimable representante de la minoría ilustrada, podernos contrastar el abismo que media entre Beristáin y Ventura Pérez. A Ventura Pérez le trae sin cuidado la cultura de élites que obsesiona a Beristáin" (Egido, 1983, p. I-III).

El autor fue ensamblador, introducido en los gremios y cofradías de la época, pero pobre y escasamente cultivado. Sus intimas convicciones, temperamento y su condición social se refleja en el Diario. En este sentido tiene interés los espacios que dedica a conflictos sociales y laborales, como motines de hambre y carestías (Enciso Recio, 1984, p. 120).

Aunque Ventura Pérez solo poseía estudios de primeras letras, enriquecido con su experiencia de ayudante de organista, sintió una manifiesta curiosidad por temas histórico-artísticos. Se dedicó a completar hasta la segunda mitad de siglo, todo un clásico, la Historia de Valladolid de Antolínez de Burgos, y dentro del gusto de aficionado a las bellas, a hacer diseños de las fachadas de los templos más destacados, así como de los escudos y blasones que campeaban por algunas de sus casas (Enciso Recio, 1984, p. 120).

Las noticias recogidas en su diario son de una enorme variedad resultando un contenido rico y heterogéneo, reflejando su personal cosmovisión de Valladolid. Teófanes Egido ha tratado de condensarlo en tres apartados: lo sagrado, la muerte y lo festivo.

Lo Religioso lo encontramos de manera pluridireccional, lo mismo habla de edificios religiosos, como de las liturgias, procesiones, sermones, uso y toques de campanas etc. de cómo el pueblo interactúa con la divinidad antes las adversidades naturales, plagas, sequias, o el terremoto de Lisboa de 1755 donde la "cólera de Dios", sacudió las conciencias pre ilustradas ya no solo en la península, sino en toda europea.

Las referencias a la cotidianidad de la muerte son constantes, accidentales, laborales, crimínales, ahogados por inundaciones, quemados en incendios, reyertas, enfrentamientos entre estudiantes y soldados, reos, ya fueran de la justicia religiosa o civil (pocos en cantidad en su momento) pero que seguía siendo un espectáculo permanente "a tono con el carácter medicinal de la pena y revelador de una sensibilidad peculiar y lejana, acostumbrada a la contemplación de brazos, manos, piernas y cabezas descuartizadas y expuestas" (Egido, 1983, p. I-XII). 
No obstante, la otra cara de la moneda era la fiesta, los vecinos de Valladolid, aprovechaban cualquier ocasión para lanzarse al regocijo público. Se celebraba con solemnidad la Semana Santa, si bien lo festivo no estaba exento, e incluso ocasiono más de un pleito o problema con la autoridad, el Corpus Christi o las fiestas del patrono san Pedro Regalado, los carnavales, anualmente o de manera extraordinaria las estancias de los reyes en la ciudad o sus proclamaciones.

La otra obra de referencia es la Historia Secular y Eclesiástica de la muy Antigua, Augusta, Coronada, muy Ilustre, muy Noble, Rica y muy Leal Ciudad de Valladolid, escrita por Manuel Canesi Acevedo (1681-1750). Poco a poco vamos conociendo más acerca de la vida y personalidad de Canesi. Su formación intelectual y sus inquietudes culturales, históricas y literarias, nos dan ciertos detalles. Sabemos nació en los primeros días 1681, del matrimonio formado por Magdalena Callejo Frías y Juan Francisco Canesi Acevedo. Su padre mayordomo de propios y rentas de la ciudad, gustaba de la poesía y la lectura, aficiones de heredó el hijo, pues en su en su Historia de Valladolid, va demostrar un amplísimo conocimiento (Almuiña, 1996, p. XVI).

Aunque 1697 lo encontramos matriculado en el primer curso de Cánones, debió dejarlo pronto (por falta de vocación o fuerza mayor) pues desaparee su nombre de los archivos universitarios, no llegando a ordenarse sacerdote, contrayendo matrimonio con María Teresa Diez, sin tener descendencia. (Almuiña, 1996, pp. XVIXVII).

Sabemos, que su oficio o modus vivendi, era el de romana o pesador en las carnicerías mayores y que sus medios económicos eran más bien escasos, procediendo la mayoría de ellos de la herencia de su esposa que murió prematuramente. El 5 de abril de 1750 hace testamento dejando como heredera principal a la niña María del Álamo, hija del escribano Manuel del Álamo, que redactó su testamento, falleciendo el 17 de ese mes en su casa de la calle de la Pasión, siendo enterrado en la iglesia de San Lorenzo (Almuiña, 1996, p. XVII).

Aunque no nos ha llegado nada de estos géneros, sabemos que escribió poesía y algunas obras teatrales que llegaron a ser representadas en el teatro de la Comedia vallisoletano. Sin embargo, su obra más importante y ambiciosa es su Historia Secular y Eclesiástica de la muy antigua, augusta, coronada, muy ilustre, muy noble, rica y muy leal Ciudad de Valladolid. Dedicada a los señores Justicia y Regimiento. Compuesta por D. Manuel Canesi Acevedo, natural de ella y creado en su excelso Ayuntamiento, que sin embargo nunca la llegó a verla publicada en vida, teniendo que esperar más de dos siglos para que viera la luz. La historia del manuscrito está llena de vicisitudes y contratiempos, ya en su testamento Canesi se refiere al manuscrito de forma clara "declaro tengo compuesta la Historia Secular y Eclesiástica de mi Patria Valladolid, es mi voluntad se penda por mi heredero y su importe se convierta en sufragios para mi alma, la de dicha mi mujer y demás por quien tenga obligación", por lo que el manuscrito estaría listo para imprenta. Sin embargo, no fue así, y el texto fue vendido por Manuel del Álamo a los Señores Estrada, quien a su vez la vende al hidalgo Vallisoletano Diego Sierra, quién al trasladarse a Palencia lleva consigo el manuscrito (Almuiña, 1996, p. XVII).

Vivat Academia. Revista de Comunicación. 15 marzo 2020 /15 junio 2020, nº 150, 1-24 
A partir de aquí se le pierde la pista, apareciendo en una librería de viejo en Madrid, de donde es comprado por el abogado bilbaíno Fidel de Sagarminaga (Almuiña, 1996, p. XVIII). Entre tanto en la ciudad el manuscrito se dio por perdido hasta 1884, cuando el historiador Juan Ortega Rubio dio la noticia de su conservación en la colección Sagarminaga en la Crónica Mercantil. Este abogado y político vasco terminó donando su biblioteca a la Diputación de Bilbao, incluido el manuscrito de la Historia de Valladolid. El archivero de esta institución, Darío de Areito, facilita en 1914 el índice de la obra para la publicación en el Boletín de la Sociedad Castellana de Excursiones. Si bien a partir de aquí el manuscrito fue conocido, extractado, consultado y frecuentemente citado en la historiografía vallisoletana, no fue hasta 1996 cuando fue publicado en su integridad. (Almuiña, 1996, p. XVIII).

Canesi dividió su Historia de Valladolid en seis libros, pero tenía pensado en agruparlos en tres volúmenes para su publicación, idea que, aunque con retraso, se respetó en 1996.

En su concepción toma como referencia clara la historia de Valladolid de Juan Antolínez de Burgos, pero con un planteamiento historiográfico distinto, al introducir Canesi, amén del estudio de los documentos, la propia tradición existente en la ciudad del devenir de los acontecimientos el manuscrito ha sido juzgado desde el punto de vista histórico de manera desigual, se ha remarcado el seguimiento sistemático a Antolinez de Burgos, la ausencia de método, sus numerosos errores, y su estilo literario complejo y barroquizante. No obstante, también se han remarcado sus valores en las ricas y sugestivas descripciones artísticas, geográficas, que aportan un rico torrente de noticias.

La tercera Fuente manejada es el Diario Pinciano, primer periódico de Valladolid, obra de José Mariano Beristáin. Nació Beristáin en Puebla de los Ángeles (México), el 22 de mayo de 1756. En el Colegio de San Pedro y San Pablo de su ciudad natal, obtuvo una beca y estudió retórica, filosofía y teología (Alonso Cortes, 1933, p.VI). El Obispo de Puebla don Francisco Fabián y Fuero, fue promovido por entonces al arzobispado de Valencia, queriendo expresamente que le acompañara. En Valencia prosiguió Beristáin los cursos de Teología y Sagrada Escritura, doctorándose en 1776. Parece ser que hacia 1782 tuvo algunas diferencias con el Arzobispo Fabián y Fuero, pues ya le encontramos en Valladolid, haciendo oposición a la prebenda Magistral vacante en la Iglesia Catedral, plaza que no consiguió (Alonso Cortes, 1933, p. VIII).

No faltó campo en Valladolid a la actividad de Beristáin. Le vemos inmediatamente ingresar e intervenir en la Real Academia Geográfico-Histórica, donde explicó elementos de geometría (Alonso Cortes, 1933, p. IX). Participó activamente en la Real Academia de Matemáticas y Bellas artes de la Purísima Concepción, desde su ingreso el 30 de noviembre de 1783, participando activamente en los más diversos asuntos. Llegó a poseer el cargo de consiliario. Las tareas del Diario Pinciano hubieron de absorber en gran parte las ocupaciones de Beristáin entre 1787-1788. 
El miércoles 7 de febrero de 1787 comenzó a publicarse el Diario, primer periódico de Valladolid. Los miércoles y más tarde los sábados salía a la luz, con un formato de 4 hojas, a una sola columna, y sin ilustraciones. Costaba medio real y estuvo impreso por Santander y posteriormente por Garrido. El precio de la suscripción por 6 meses era de doce reales. El promotor, director, administrador y redactor era José Mariano Beristáin. Pero el inquieto periodista no estaba solo en la tarea; colaboradores más o menos ocasionales fueron: Floranes, Alonso Ortiz, Manuel de Villades, director de la Universidad, Ramón Fernández Correa, Andrés del Corral, Félix Martínez López y Tomas Moyano. El periódico tuvo una corta vida, apenas de diecisiete meses (Enciso Recio, 1984, p. 121).

La vida de Beristaín imbuida en las ideas ilustradas, se desarrolló activamente hasta 1788, fecha en la que decide trasladarse a Vitoria para opositar a la canonjía electoral de Vitoria, plaza que obtuvo, abandonando su cátedra de Valladolid. No ocupó durante mucho tiempo el puesto, ya que a fecha de 1790 acompaña al Obispo de Vitoria a su nueva sede en Puebla, donde Beristáin no consigue asentarse dentro del cabildo, volviendo a su sede en Vitoria. En 1794, se traslada de nuevo a México, donde se introduce definitivamente en la política mexicana hasta su muerte, ocurrida el 23 de marzo de 1817 (Alonso Cortes, 1933, pp. XXVIII-XXX).

\section{DISCUSIÓN}

\subsection{La celebración de la semana santa y el siglo XVIII. Del esplendor al ocaso}

Las celebraciones de la Semana Grande de Valladolid comenzaron el siglo XVIII con un gran esplendor, que se vería incrementado durante el primer tercio del siglo. Las cofradías ya tenían su principal patrimonio, los pasos. Durante el siglo la tarea fue conservarlos. El caudal económico se comenzó a destinar a otro tipo de obras, especialmente al embellecimiento de sus respectivas sedes. Así la cofradía de las Angustias edifica de nueva planta la capilla, donde había de rendirse culto con el máximo esplendor a su titular, la Virgen de las Angustias. Ventura Pérez nos da noticia del acto:

En este año de 1710 se colocó a María Santísima de los chuchillos en su nueva capilla, estaba toda la ciudad muy adornada de Altares y muchas alhajas de plata; y con el señor archiduque (Carlos de Austria) estaba en España, se sonaba que venía a esta ciudad a causa de haber enviado un tambor a pedir las llaves, y la ciudad haberle respondido que las llaves eran de Felipe V, sin embargo que si las quería que viniese a por ellas. Con este motivo la gente empezó a decir que venía el enemigo, y en una noche desmontaron la de plata que había en la calle y en su lugar lo adornaron con pasta. Y el archiduque no vino (Pérez, 1885, p. 30).

La de Jesús en 1704 estrena retablo para el nazareno (Pérez, 1885, p. 22); y la de la Piedad completa su iglesia con capilla mayor, sacristía y camarín nuevos. Ventura Pérez describe las fiestas de colocación de Nuestra Señora de la Piedad en su capilla mayor (Pérez, 1885, p. 91) y, años más tarde del santísimo (Pérez, 1885, pp. 126-128);

Vivat Academia. Revista de Comunicación. 15 marzo 2020 /15 junio 2020, nº 150, 1-24 
y la Pasión que no iba a ser menos, decide sacar en procesión, desde 1705, a la imagen de Nuestra Señora de la Pasión, titular de la misma.

Todas estas novedades hacen ver el enorme poderío económico que poseían las hermandades penitenciales, y por extensión sus celebraciones externas, que no se circunscribían tan solo a los días de la Semana de Pasión, sino que además cada penitencial celebraba su festividad. La Vera Cruz, el tres de mayo (Pérez, 1885, p. 496); las Angustias la Encarnación el 25 de marzo (García Chico, 1964, pp. 11-12); la Pasión, San Juan degollado (Canesi, 1996, p. 27), donde participaban todas las cofradías penitenciales, acompañando la procesión o montando altares. No hay que olvidar la activa participación de las cofradías en la celebración del Corpus, la canonización de San Pedro Regalado, la beatificación de San Simón de Rojas, u otras menos festivas como las rogativas por la lluvia (Pérez, 1885, pp. 289-290).

La fama de las procesiones de Valladolid era ya muy celebra por buena parte del orbe católico. La obra de Canesi nos permite una exacta visión de cómo se celebran las procesiones de Semana Santa en la primera mitad del siglo XVIII: el número y la descripción de los pasos que las formaban, sus horarios, itinerarios, como estaban organizadas y como se constituían las cofradías penitenciales, que por el años 1730 estaban en la cima de su esplendor, y por qué en 1731 emprenderán una vertiginosa marcha hacia el ocaso, haciéndose ciertos los augurios de Canesi que las llevarán a su total desaparición en un siglo. En el libro tercero de su Historia de Valladolid, en el capítulo dos, que titula "De las cinco cofradías penitenciales que se instituyeron en esta ciudad y de las procesiones de Semana Santa, que son tan aplaudidas en toda Europa", nos relata estos hechos, que luego comentaremos. A continuación, describe los cortejos.

La primera procesión salía a las nueve de la noche el Miércoles Santo de la Penitencial de la Vera Cruz, camino del convento de San Francisco. Alumbraban más de 600 personas, repartidas a tramos de unas 60 a 80 entre paso y paso. Cerraba la procesión el párroco de Santiago, de cuya jurisdicción dependía la Vera Cruz. La procesión se completa con los Alcaldes del Crimen, el Corregidor o su Teniente, y representantes de los tribunales. Este cortejo estaba formado, según palabras de Canesi, por los siguientes pasos: "La oración que hace Cristo en el Huerto, el Azotamiento, la Coronación, el de José de Arimatea y Nicodemos, bajando a Cristo de la Cruz, presente su Madre Santísima" (Canesi, 1996, p. 23).

La segunda procesión salía entre las 4 y las 5 de la tarde del Jueves Santo de la Ermita de Nuestra Señora de la Pasión (antiguamente lo hacía desde el convento de Trinitarios Calzados), cruzando la Plaza Mayor llegaba al Ochavo, continuando por Platería, Cantarranas, Cañuelo y cruzando por Mesón de Magaña entraba en la catedral. Una vez fuera bajaba por Orates a Mercaderes de Paños y Sedas, continuando por Lonja a la Plaza Mayor y de aquí a finalizar a "su sagrada casa" (Canesi, 1996, pp. 23-24). La alumbraban más de 700 personas de "de todas las artes y ejercicio", y la cerraba el párroco de San Lorenzo, a cuya demarcación pertenecía, y 
como era tradicional, los Alcaldes del Crimen, con el Corregidor y sus ministros. Los pasos que procesionaban con ella eran:

El Azotamiento, Jesús Nazareno, y el Cirineo ayudándole a llevar la cruz, un judío con la lanza hiriéndole el costado y las dos mujeres que salieron al encuentro de Jesús y la una le limpio el rostro en la calle de la amargura, llamada Verónica. Cristo Orando a su eterno Padre, a este señor llaman el del Perdón y le ponen en el Campo grande cuando hay quemados. Cristo en la Cruz y los judíos tirando con unas sogas de ella para enarbolarla, y los dos ladrones a su vista en el suelo en pie. Cristo en la Cruz y San Juan y la Magdalena llorando y su santísima madre y dos judíos partiendo sus vestiduras y túnica in consutil. Nuestra Señora de la Pasión con su hijo precioso en el regazo, este paso sale desde 1705 (Canesi, 1996, p. 24).

Concluida la procesión de la Pasión, salía a la calle el tercer cortejo desde el Convento de San Francisco. Esta procesión era la del regreso de la Cruz a su iglesia, con idéntico recorrido que la del miércoles, pero a la inversa. Salía del convento de San Francisco en la Plaza Mayor, continuaba por las calles de la lonja, Ochavo, Platería, Cantarranas, Cañuelo hasta la catedral, de aquí bajaba por Petrimería a Mercaderes de Paños, subiendo por Platerías a su templo de la Vera Cruz (Canesi, 1996, p. 23).

A las 9 de la noche del mismo Jueves Santo salía la cuarta procesión, la de las Angustias, finalizando su recorrido en el convento de San Pablo, donde permanecía hasta el día siguiente. Alumbraban más de 600 personas. Cerraba la procesión la parroquia de la Catedral, por ser su distrito, y la sala del Crimen con sus ministros y pajes. Los pasos que formaban esta procesión según Canesi son:

Un Cristo Crucificado. Otro en el regazo de su Madre santísima cuando descendió de la cruz los dos ladrones puestos en sus cruces. Otro Cristo en el Sepulcro a quien alumbra un claro de sacerdotes... Otro Cristo en el sepulcro y los guardias que le pusieron dormidos. Nuestra Señora de los cuchillos, imagen de especial devoción y hechura, como las más de ellas (Canesi, 1996, p. 24).

El historiador no indica el itinerario, pero se supone que, como el caso de la Vera Cruz, seguiría el mismo que hacía el viernes, pero a la inversa.

La quinta, la de Jesús Nazareno, salía de su ermita (anteriormente lo había hecho de desde el convento de los Agustinos Calzados) el Viernes Santo "al romper el alba, más por no poder asistir los que componen tan temprano se ha transferido a las 8 de la mañana" (Canesi, 1996, p. 24). La comitiva estaba formada por los cofrades y diputados de la cofradía, así como ocurría "en las demás procesiones van mucho de disciplina y armados" (Canesi, 1996, p. 24). Respecto al itinerario era el mismo por donde caminaba la Pasión, excepto cuando volvía de la catedral y llegaba a la calle Mercaderes Paños cortaba por Cebadería, desde donde llegaba a Santiago. Los pasos que sacaba a la calle eran: "Jesús Nazareno... Síguese cuando estaban aharrenando la cruz para ponerla en ella. Cristo crucificado y un judío clavando el rótulo en lengua 
hebrea, griega y latina y dos sayones partiendo la túnica y jugándosela a los dados" (Canesi, 1996, pp. 24-25).

La siguiente procesión que describe Canesi durante el Viernes Santo, no estaba vinculada a ninguna de las cinco cofradías penitenciales. La procesión salía del convento del San Pablo, una vez que había terminado el sermón de la Soledad de María, con la asistencia de toda la comunidad y más de veinte religiosos vestidos con dalmáticas donadas por su patrono el Duque de Lerma con velos negros en la cabeza. En una fuente llevaban los atributos de la pasión de Cristo. Concurre a ella la antiquísima imagen de Nuestra Señora del Rosario. En Medio de la comunidad portaban a la imagen Nuestro Señor del Sepulcro, de ahí el nombre de "Procesión del Santo Entierro". La ceremonia se realizaba en la capilla abierta al claustro llamado del sepulcro, por donde salía dando vuelta a la plaza del Palacio Real, para entrar por la puerta del claustro para acabar en la capilla donde había partido. (Canesi, 1996, p. Procesión del Santo Entierro 25).

De la ermita de la Piedad partía la séptima procesión, a las cinco de la tarde, antiguamente lo hacía desde la Merced Calzada. El cortejo se componía de "Gente de todos los ejercicios y artes y muchos de distinción". En el último tramo, que era el de Nuestra Señora de la Soledad era según Canesi muy lúcido con más de trescientas personas de devoción y muchas de disciplina. Cerraba la procesión el párroco y los capellanes de El Salvador y el resto de autoridades civiles (Canesi, 1996, p. 25). Los pasos que llevaba eran:

Cristo con la túnica encarnada sentado y detrás de la cruz y los atributos de pasión, repartidos en ella de talla. Longinos a caballo dando la lanzada a Cristo ya crucificado y su Madre santísima y S. Juan a su vista. La cruz sola en que murió Cristo. José de Arimatea y Nicodemus con Cristo difunto en los brazos cuando le bajaron de la cruz, la que está a su vista, y la Magdalena y otra figura abriendo el sepulcro. Nuestra Señora de la Soledad a vista de la cruz, desconsolada por la injusta muerte de su hijo amado (Canesi, 1996, p. 25).

La octava y última procesión era la que saliendo de San Pablo regresaba a Las Angustias, repitiéndose todo con el día de antes, pero con mayor ostentación y grandeza, rodeada de una especial solemnidad. El Cristo en el Sepulcro iba acompañado de los sacerdotes que querían alumbrarle, mientras que la Virgen de los Cuchillos, que cerraba la procesión era iluminada con hachas, siendo acompañada por "muchos hombres armados" y numerosos penitentes". El desfile bajaba desde el Convento de San Pablo hasta la Plaza del Almirante por Plazuela Vieja, continuando después por Cantarranas, y Platerías hasta mercaderes de Paños, después por Chapineros subía a la Catedral, como lo hacían las demás. Una vez fuera del templo catedralicio cruzaba el Esgueva por el puente de Magaña, hasta las Angustias, donde terminada (Canesi, 1996, pp. 25-26).

Aunque es cierto que ésta procesiones eran las más vistosas, existieron otras también citadas por Canesi. La que se desarrollaba el Domingo de Ramos, y que 
estrictamente, debería de ser la primera: "La cofradía de la Cruz lleva un paso muy vistoso del Triunfo de Cristo en la entrada de Jerusalén" (Canesi, 1996, p. 20) y la que cada parroquia y convento celebraba el día de Pascua de Resurrección con el Santísimo.

Pese a este esplendor desplegado por los cortejos penitenciales, no estuvieron exentos de contratiempos más o menos fortuitos. Ventura Pérez más pendiente de la anécdota peculiar, nos describe los accidentes de 1725:

El día 28 de marzo de Dicho años no salió la procesión de la Cruz hasta las diez de la noche, a causa de llover a cántaros, y el día 29, viernes santo (digo, jueves santos) salió la procesión de la Pasión por la tarde, lloviendo, y la de la cruz no pudo salir más que hasta sus casas, y la de las angustias salió muy tarde y lloviendo. El día 30, viernes, santo, salió la procesión de Jesús, sin llover, pero con miedo... y por la tarde salió la de la Piedad, lloviendo y por la noche salió la de las Angustias, muy tarde y nevando. (Pérez, 1885, pp. 72-73).

La precaria organización y el anárquico desarrollo de las procesiones originaron a veces disturbios que contribuyeron a su decadencia. La autorización, organización y vigilancia del desarrollo de las procesiones estaban sometidas a la Sala del Crimen de la Real Chancillería y así seguirá hasta que es suprimida en el siglo XIX. Las procesiones de Semana Santa Valladolid, ya tenían en estos momentos una antigüedad de más de dos siglos y durante estos, es lógico que se hubiesen originado incidentes, en algunos casos de gran importancia. El sucedido en 1714, tuvo unas consecuencias inmediatas. En la procesión que había salido el Jueves Santo de las Angustias a San Pablo a las nueve de la noche; los alcaldes del Crimen salieron de ronda en ella, y porque, no se colocaban los estandartes como ellos querían o porque se habían introducido en el claro de los escribientes, se levantó un motín en el que se prendieron algunos oficiales de la pluma; el Consejo Real de Castilla por estas y otras razones desterró a los Alcaldes José de la Cruz, Juan Antonio Osorio de Velasco y Alonso Yañez de Abacusa (Pérez,1885, p. 41-42 y Canesi, 1996, p. 53). Comenta Canesi que "Este asunto despertó a las musas y muchos ingenios compusieron papeles muy discretos y chistosos sobre el asunto" (Canesi, 1996, p. 53)

El incidente que acabamos de reseñar traerá gravísimas consecuencias, pero en realidad no había sido entre cofradías, muy habituales en los siglos anteriores, sino entre personas pertenecientes o sometidas a un mismo estamento, la Chancillería.

La sala del Crimen no olvidó el correctivo que le impuso el Consejo Real de Castilla y pocos años más tarde, en 1731, el presidente don Andrés Bruna, dicta un auto, en el que se dispone que todas las procesiones deberían de salir a las horas asignadas en sus cartas ejecutorias, y que los alcaldes y estandartes de las cofradías no den agasajos públicos o secretos bajo ciertas penas. El Auto tiene dos partes; la primera obliga a que todas las procesiones salgan de día, cosa materialmente imposible, como el mismo Canesi expresa "porque si el Jueves Santo se hacen tres procesiones y, cada una necesita a los menos dos horas de tiempo, ¿cómo podría conseguirse el fin, aunque empezase la primera a las 2 de la tarde? (Canesi,1996, p. 
56); y la segunda, con la prohibición de los agasajos o refrescos, suponía la desaparición de los ingresos de las cofradías.

Las consecuencias en las celebraciones de ese año no se hicieron esperar, y bajo el explícito título de "Semana Santa Alborotada" nos lo comenta Ventura Pérez:

Se quitaron los fornos que tenían los escribientes y de más estandarditas por la semana santa, y se mandó que las procesiones todas saliesen de día, lo cual se ejecutó así por ese año, anticipándolas todas las que salían de noche, como el llevar los pasos de la Cruz que se llevaban el miércoles por la noche se llevaron por la tarde, y los de las Angustias que se llevan el Jueves Santo después de la procesión de la Cruz, se llevaron dicho jueves por la tarde y todas las demás procesiones se trastocaron. (Pérez, 1885, p. 108).

Más espectacular resulta el relato de Canesi en relación con la procesión de la Vera Cruz el miércoles, describiendo como se desarrolló el cortejo "sin oírse otra música que los gritos de la gente que se aprehendía y de los alguaciles que las molestaba, lamentos y quejas de los oficiales de la cofradía y de cuantos la veían; todo era temor y confusión" (Canesi, 1996, p. 57).

A raíz de estos acontecimientos comenzó un tira y afloja entre la Chancillería y las penitenciales, que concluyó en 1734 con la presentación de las últimas alegaciones por parte de las cofradías contra el citado auto, asegurando que, de mantenerse las prohibiciones apeladas, no habría ninguna procesión y los perjuicios ocasionados al comercio, al público y a la imagen de la Ciudad serían muy importantes. La Sala del Crimen no tuvo en cuenta alegaciones y fue necesario apelar al Consejo Real de Castilla, que las aceptó, mandando que las Cofradías Penitenciales "guarden la costumbre que hasta ahora ha tenido en cuanto a agasajos, refrescos y demás funciones, pero no deberán tener formos ni juegos prohibidos, en las salidas se mantendrán las horas y costumbres y que todos los asistentes vayan con modestias y veneración". El presidente de la Sala del Crimen, no conforme con esta resolución y usando de su autoridad en contra de la mayor parte de los jueces, acude al rey, que estaba en Sevilla con la Corte, con el parecer a su favor del Obispo, y consigue que las procesiones salgan de día y se aplique el auto dictado.

Mientras tanto las celebraciones no volvieron a tener el esplendor perdido, iniciándose una cuesta abajo incontrolable que podemos seguir por los datos ofrecidos por Ventura Pérez. En 1736 la procesión de la Vera Cruz tiene problemas con el párroco de San Miguel (Pérez, 1885, p. 136), que reclama sus derechos de jurisdicción y no va a San Francisco, y un año más tarde se ve obligada a llevar los pasos a San Francisco en la mañana del jueves (Pérez, 1885, p. 144). En 1742 surgen problemas para salir a la calle en las cofradías de las Angustias y Piedad, ya que no se armaron sus pasos "solo pusieron a Nuestra Señora de la Soledad y al Cristo de la Humildad en andas, pero así se quedó; a Nuestra Señora de los Cuchillos no la bajaron de su trono", situación que vuelve a repetirse al año siguiente (Pérez, 1885, p. 143). 
El primer síntoma de decadencia que se acusa en las cofradías penitenciales lo vuelve a recoger Ventura Pérez, en 1762, aunque en su escueto apunte no estaba la causa, motivada sin duda por la falta de cofrades para portar a hombros determinados pasos de la penitencial de la Piedad, al decir que aquel año redujeron el de la Lanzada ol Longinos y quitando del todo el del sepulcro (Pérez, 1885, p. 350). Siete años más tarde fue la cofradía de la Vera Cruz la que se vio obligada a una operación muy similar al salir solo "con el paso del Huerto, sin soldados, solo el Señor y el Ángel en unas andas con un corredorcito, y el Señor en la columna solo en otras andas" (Pérez, 1885, p. 425); en cambio las restantes cofradías no introdujeron por entonces ninguna novedad en los suyos. Al año siguiente la cofradía de las Angustias, aunque montó sus pasos debió de tener problemas en su desplazamiento con ellos desde su sede hasta el vecino convento de San Pablo y viceversa (Pérez, 1885, pp. 437), y en 1771, el mismo diarista asegura asegura que no salió la procesión de la Vera Cruz alegrándose en cambio de que la cofradía de la Piedad pudiera sacar tres de sus pasos: el de Longinos, el Cristo de la Humildad y Nuestra Señora de la Soledad (Pérez, 1885, pp. 448-449). En 1770 la cofradía de las Angustias prescindió prácticamente de la procesión en público, y andaba "con un claro muy pobre". Desde 1777, eta misma cofradía tuvo que prescindir de las túnicas (Pérez, 1885, pp. 490 y 506).

Sin duda algo estaba cambiando en las prácticas devocionales de la Semana Santa. No puede olvidarse que el Viernes Santo de 1752 "dio principio la tramoya del descendimiento a lo vivo en el comento de la Santísima Trinidad de Calzados" (Pérez,1885, pp. 349-350), y esta práctica provocaría cierta competencia con el montaje del paso del Descendimiento de la Vera Cruz e incluso con el de la Piedad de la Penitencial de las Angustias ya que en la ceremonia se conseguía con la actuación de figurantes un efectismo superior al que provocaba el realismo de los paso, se aminoraba sensiblemente los gastos que ocasionaba el gran número de porteadores que cargaban estos y se evitaba la posibilidad de tener que lamentar desgracias como la del "reventado" del año 1741 (Pérez, 1885, p. 189).

Las procesiones se siguieron celebrando de una forma muy precaria, cuando de manera excepcional salía alguna más o penos decente, y que recordaba vagamente al antiguo esplendor era recibida por el pueblo con auténtica algarabía y fervor, como hecho extraordinario según se desprende de las palabras de Ventura Pérez:

y la Piedad salió solo con el claro de devoción y estuvo muy buena porque salió el paso de Longinos, el Cristo de la Humildad y Nuestra Señora de la Soledad. Todos los devotos cogieron sus estandartes y los cocheros cogieron su cruz y a casa; cogieron su estandarte y de regocijo y alegría tuvieron su refresco por haber sacado a la virgen y haberla dejado toda la cera que llevaban los alumbrantes (Pérez, 1885, pp. 448-449).

Como se ve la cofradía no organiza el cortejo, eran los devotos a título individual quien se encarga de sacarlo a la calle.

En realidad, a estas alturas, las penitenciales eran víctima de los ataques ilustrados. Los informes elevados a la autoridad en 1773 por el intendente corregidor

Vivat Academia. Revista de Comunicación. 15 marzo 2020 /15 junio 2020, nº 150, 1-24 
Ángel Bustamante, permiten rastrear algunos de los aspectos más interesantes y populares de las cinco cofradías. Comenta que, salvo la Pasión, las demás habían perdido su finalidad asistencial siendo su principal fin por entonces el devocional y procesional, según el lustrado verdaderas escenas de escándalo, pues con la excusa de las procesiones, el pueblo las calles y los balcones estaban abarrotados de "gente de ambos sexos, tan lejos de la compasión y devoción, que más parece celebridad de Carnaval". No encuentra el intendente-corregidor palabras para expresar las indecencias y escándalos que estas procesiones provocan en toda clase de personas, particularmente "en la procesión que llama del Entierro de Cristo, la cual hace la cofradía de las Angustias", que curiosamente salía al anochecer (Egido, 1984, p. 181). La batería del Despotismo ilustrado contra las cofradías se centró, además de en su hostilidad hacia cualquier forma de asociación, en dos motivos fundamentales: los gastos que funciones y procesiones ocasionaban al alcaldes, mayordomos y cofrades, dando a entender que son casi la ruina de España: y en la incompatibilidad de una religiosidad parajansenista, rigurosa, con estas expresiones populares.

En resumen, el estrecho control que el Tribunal de la Real Chancillería de Valladolid ejerció sobre las cofradías para evitar enfrentamientos entre ellas, alborotos y gastos superfluos que no podían afrontar sus cofrades, el enfriamiento de la devoción, que se acusaba principalmente en las clases dirigentes, la progresiva introducción de las ideas ilustradas, la cortedad de medios económicos que impedían el sostenimiento del culto en cinco iglesias penitenciales, provocaron el desánimo y desinterés por continuar manteniendo, con el mismo espíritu, el esplendor o la notoriedad que habían alcanzado las procesiones en sus días más brillantes. Incluso el precipitado abandono en 1789 por parte de la cofradía de la Piedad de su sede penitencial, y su establecimiento en la vecina San Antón, constituyen el mejor ejemplo de la precariedad en que las cofradías comenzaron el siglo XIX, acentuándose con la nueva intervención en 1806 de la Sala del Crimen de la Real Chancillería, intentado reducir todas las procesiones a una única el Viernes Santo, y sobre todo con la guerra de Independencia, que supuso un duro golpe, del que difícilmente se recuperarían.

\subsection{Los pasos procesionales. Esplendor y crisis. El papel de la real academia de Bellas Artes}

Existe un abismo temporal entre las descripciones de Pinheiro da Veiga a comienzos del siglo XVII y la de los viajeros y eruditos del siglo XVIII, que no se cansan de loar sus pasos, pero siempre desde un punto de vista artístico. En cambio, Ventura Pérez e incluso Canesi más con el discurso popular, hablan de los pasos sin asombro y con naturalidad, con una aparente despreocupación artística.

No es patrimonio del siglo XVIII, las apreciaciones personales, unánimemente positivas, acerca de los conjuntos procesionales. Ya en 1606 el embajador portugués en la efímera corte vallisoletana de Felipe III, consideraba a los pasos que pude ver en las procesiones como realmente excepcional "porque en lugar de nuestras banderas pintadas, traen pasos de bulto, de altura proporcionada, los más bellos y 
hermosos que se puedan imaginar, porque estos de Valladolid son los mejores que hay en Castilla, por la proporción de sus cuerpos, la hermosura de sus rostros y aderezo de sus figuras, que todo es de la misma materia de cartón y lino, de que están formados: y si va algún vestido, gorra o capa exterior es de brocado o tela, de suerte que parecen muy bien" (Pinheiro da Veiga, 1989, p. 44). Lamentablemente de los pasos llamados de "papelón", descritos por Pinheiro, ninguno de ellos se ha conservado, ya que el de la borriquita, el único de este material que ha llegado hasta nosotros, no es citado por él. La explicación de la desaparición de estos pasos es muy sencilla. Durante el siglo XVII las procesiones fueron encargando pasos nuevos realizados en madera, por ser este material mucho más duradero que las telas encoladas y el cartón. El primero en abrir fuego en la renovación de los pasos fue Francisco de Rincón, con la Exaltación para la Cofradía de la Pasión, siguiéndole Gregorio Fernández que llego a su superar a su maestro y que fue realmente la figura clave para entender la renovación que se estaba realizando. Después de Fernández, se continuaron haciendo nuevos conjuntos, a lo largo de todo el siglo XVII, pero la sombra de Fernández era demasiado importante, y sus modelos fueron repetidos constantemente por otros artistas, en muchas ocasiones obligados por los comitentes.

La fama de estos conjuntos fue aumentando progresivamente y de manera gradual durante el siglo XVIII. Las palabras de Palomino, son suficientemente elocuentes "los pasos de la pasión de Nuestro Salvador de aquella ciudad, que a juicio de grandes artífices que los han ido a ver ex profeso, son lo más selecto que tiene España" (Palomino, 1724/1986, p. 89). Canesi, que evidentemente conoció todos los pasos y participó en las procesiones, no ahorra ningún tipo de elogios al referirse a ellos: "todas las hechuras de los pasos son primorosas, especialmente las de Cristo y su Madre, que en todo son perfectas y con mucha veneración y lastima en cada cosa que representan, porque en los afectos de un ánimo afligido están con mucha propiedad y viveza. Las del Rey de la Gloria majestuosamente infunden pavor y reverencia. Y las de María Santísima, con dulzura, rinden a su amor los más rebeldes corazones" (Canesi, 1996, p. 102). Estas palabras las tenemos que considerar como salidas de un auténtico "Fanático" o enamorado de sus procesiones, la de un vallisoletano que las vive y se lamenta de la crisis de estas.

Las palabras de Canesi son el último testimonio de una mentalidad que mediando el siglo XVIII estaba languideciendo y dejando paso a un sentimiento ilustrado y político que como se ha visto, chocaba de frente con todo lo que era la Semana Santa. Claro está que este pensamiento, por entonces no muy extendido, era el practicado por las élites del poder, y, sobre todo, las que poseían los instrumentos de opresión. Podría pensarse que la alta estima que se rendía a los conjuntos procesionales, tanto por los locales como por los foráneos, decayera con la nueva mentalidad, y lo que antes eran loas, ahora se transformaran en desprecios. Paradójicamente esto no ocurrió, sino más bien se incrementó su valorización añadiéndose nuevos puntos de vista, que hasta ahora no habían aparecido: la conservación y restauración de los conjuntos procesionales. Sin embargo, las primeras voces preocupadas con el estado de conservación de estos juntos, no se escucharon desde la ciudad si no desde la Real Academia de San Fernando de Madrid. Antonio Ponz, secretario de esta institución 
clamaba de que los pasos "padecen sus trabajos de Semana Santa, pues en armar los Pasos y llevarlos por las calles, como que son máquinas grandes, siempre se rompen algunas partes...que es mucha lástima" (Ponz, 1788, p. 53). Los planteamientos conservacionistas de Ponz fueron recogidos ya desde Valladolid, por el ya citado Mariano Beristáin, quien se lamentaba del estado de deterioro de estos conjuntos y lo poco que hacían sus paisanos para remediarlo. Argumentaba que los conjuntos eran expuestos durante la Semana Santa quedando a la intemperie en la plaza Mayor a la merced de los caprichos de la climatología, y que la manera de llevarlos (poco decorosa y ordenada) los exponía a cualquier caída. Proseguía, no sin ironía, que, "si salían felizmente de la semana santa, las figuras se tiran y se arrinconan, entregándolas: a la jurisdicción de la polilla, al polvo destruidor, a la humedad y lobregueces de un salón oscuro, donde mantienen un año esperando, como los padres de Limbo la venida de otra Semana Santa" (Beristáin, 1933, pp. 102-103). No quedaron aquí los lamentos del ilustrado, ya que en el caso de necesitar estas figuras una restauración, esta quedaba en manos imperitas que las desfiguraban por completo como ocurrido con la Virgen del descendimiento, el Jesús de la Coronación y el Ángel del Huerto entre otras" (Beristáin, 1933, p. 102). Para intentan paliar la situación, Ponz se inclinaba por que determinadas figuras (entendemos que las de mejor calidad) "quedasen en los templos, adonde fuesen los fieles a verlas, y venerarlas en tales días" (Ponz, 1788, p. 54). Beristáin por su lado, más conocedor del medio vallisoletano, proponía que las imágenes sagradas quedaran en las iglesias a la vista del pueblo, mientras el resto, fundamentalmente soldadesca que era almacenada al desmontarse los pasos, fueran recogidas por la Real Academia de Bellas Artes y Matemáticas de la Purísima Concepción de Valladolid, nacida en 1779, "que sabrá cuidarla mejor", añadiendo otro factor interesante que sirvieran para modelo y copia. Sin embargo, es consciente de la falta de competencia de la academia en este sentido al argumentar que para que la academia pudiera hacerse cargo de ellas, debía pasar directamente por una decisión real "Parecerá esto dura a las Cofradías y aun injusto, pero el rey puede hacerlo" (Beristáin, 1933, p. 54).

El reconocimiento y el valor dado a los conjuntos procesionales por la Academia de la Purísima Concepción, fue intachable. Existen numerosos datos que prueban el interés hacia algunas de estas piezas, que empezaron a servir de modelo para los ejercicios de los alumnos, o haciendo copias y vaciados de ellas. Así en el año de 1802, y aprovechando la presencia en Valladolid de unos vaciadores de yeso, se les encargo los moldes y vaciados de las figuras de los dos ladrones, del Paso de la Piedad de Gregorio Fernández, aun custodiados por su cofradía de las Angustias, obteniéndose tres copias de ambos. Una se quedó en Valladolid ordenando que "se pongan a manifiesto en la sala de la Academia para que sirvan de modelo y los moldes se custodien", vendiéndose las otras dos, una a la Real Academia de Bellas Artes de San Fernando, y la otra a la de San Carlos de Valencia (Agapito y Revilla, 1925, pp. 114-117).

Por aquel año de 1802 ya hacia bastantes años que los pasos más monumentales habían dejado de salir, argumento que sirvió a la Academia para dirigirse el 11 de julio al rey Carlos IV, denunciando la situación de abandono y desidia a los que

Vivat Academia. Revista de Comunicación. 15 marzo 2020 / 15 junio 2020, nº 150, 1-24 
estaban sometidos los conjuntos procesionales. Antes tales argumentos el rey atendió la denuncia y resolvió Real orden de 30 de septiembre de aquel mismo año, canalizada a través de su Estado y del Despacho, que la Academia fuese la encargada de cuidar "de la conservación de aquellos preciosos monumentos de las Artes, procurando que no maltraten ni se desfiguren, a fin de que la ciudad de Valladolid pueda tener a la vista de los discípulos de las Nobles Artes modelos dignos de imitar y a la de los inteligentes y aficionados objetos de admirar" (Agapito y Revilla, 1925, pp. 102-103). Bosarte, bien relacionado con la Academia de San Fernando, se hace eco de esta noticia "semejantes renovaciones bárbaras (refiriéndose al abandono de las imágenes y su lamentable estado de conservación), movieron a la Real Academia de Valladolid a presentar a S. M. En 11 de julio de este año exponiendo el desorden que se notaba en renovar imágenes antiguas de mucho mérito: á cuya exposición se sirvió su S. M. Expedir su Real Orden en 30 de Setiembre encargando a la Academia velase en impedir este abuso; Y otra igual orden se comunicó al Capitán General de la provincia con la misma fecha" (Bosarte, 1804, p. 201).

La Real orden no tardo en cristalizar, con la creación de una comisión que se encargaría de inventariar y conservar las figuras que componían los pasos procesionales. Una de las primeras medidas de la misma fue la visita a las cinco iglesias penitenciales, efectuada de los comisionados por la Academia, los pintores Diego Pérez Martínez y Leonardo Araujo en mayo de 1803 (Agapito y Revilla, 1925, pp. 104), redactando un primer inventario en el que señalaban que las figuras que se encontraban en los almacenes de las congregaciones estaban "muy maltratados...mal retocadas...con poco aseo", y algunas de los soldados "echo pedazos" y otras enteramente destruidas, señalando que faltaban cuatro esculturas (dos de la vera cruz y otras dos de la pasión) desconociendo que habían sido mandadas a Madrid a don Bernardo de Iriarte, con destino a la Real Academia de Bellas Artes de San Fernando en 1797. Ante tal situación la Academia de Valladolid, decidió tomar cartas en el asunto, desplegando su maquinaria administrativa escribiendo al Presidente de la Real Chancillería de Valladolid. En la misiva, que se puede considerar verdadero precedente en la conservación del patrimonio, y su restauración por expertos actual, que requería al presidente que diera la orden que los pasos solo salieron a la calle durante la procesión y no estuvieran expuestos a la intemperie en las puertas de las iglesias, con el fin de evitar restauraciones y retoques, (algunos, como los realizados por la -Vera Cruz en sus imágenes, muy sonados, que las desfiguraban por completo.

Pasada la guerra de la independencia (abril 1815) la Real Academia volvió a interesarse por el estado de conservación de los pasos procesionales, la situación tras este periodo bélico, aunque entendible ante la situación de postración de las cofradías era lamentable. Los pintores comisionados al efecto Ceferino Araujo y Pedro González Martínez, describían como la estaban tan destrozadas que lo raro es que existiera una completa "faltan cabezas, brazos y un sinfín de piezas", o que solo queda de ellas "que una pierna o un brazo". Si bien estas palabras deben traducir el estado de las figuras secundarias, no corrieron mejor suerte aquellas figuras principales que se veneraban en las iglesias. Así las imágenes de la Vera Cruz del

Vivat Academia. Revista de Comunicación. 15 marzo 2020 / 15 junio 2020, nº 150, 1-24 
ángel de la oración o la imagen de la virgen de la Vera Cruz, fueron tan burdamente repintadas que quedaron completamente desfiguradas (Urrea, 200, p. 17).

Ni que decir tiene que no se hizo absolutamente nada para remediar tal situación, pues años después, en un nuevo reconocimiento de la Academia de la Purísima Concepción, en 1828, llevado a cabo el canónigo José Berdones, el pintor Pedro González y el arquitecto Pedro García, donde comprobaron el pésimo estado que seguían mostrando las figuras, comentando no sin cierta ironía que parecían que "habían salido de alguna zaurda", lamentándose a renglón seguido (como venía siendo tónica) que podían ser reparadas por la Academia, concluyendo que como la salida procesional de los conjuntos iba a ser complicada en un futuro, por la necesidad de hacer gasto en nuevos tableros y andas y el poco dinero que tenían las penitenciales, la medida más oportuna seria trasladarlos a la Academia" (Urrea, 200, p. 17).

Sin embargo, esta medida quedo, en principio, en suspenso, y no fue hasta pasada la desamortización de Mendizábal, momento es que la Academia recibió el encargo de almacena en su sede los objetos procedentes de los conventos desamortizados de Valladolid y su provincia, cuando se verifico el traslado. Entre tanto la Academia acuciada por la falta de espacio para almacenar las piezas desamortizadas en su sede de la actual calle Fray Luis de León (antigua de Pedro Mazuecos), consiguió, en 1838, el Colegio de Santa Cruz como nueva sede, con el fin de habilitar allí un museo con las numerosas obras de arte almacenadas, de tal suerte que se aprovechó este momentos de traslados de una sede a otra, para recoger finalmente en el mes de abril de 1841, algunas "efigies" de las iglesias penitenciales (Agapito y Revilla, 1916, p. 15).

La recepción de las figuras fue un verdadero caos perdiéndose su ubicación en los distintos pasos, si bien algunas fueron marcadas según el lugar de procedencia, un cruz "+" (Vera Cruz), una "P" (Pasión), o una "J" (Jesús Nazareno), no obstante habrá de esperar a esperar a principios del siglo XX, con la figura de Agapito y Revilla, para que se empezara a solucionar el tremendo rompecabezas que suponía el montaje de los pasos de nuevo con las figuras conservadas, dentro de una reforma de la Semana Santa promovida por la figura del Arzobispo Gandasegui, pero eso ya es otra historia.

\section{CONCLUSIONES}

Como hemos podido comprobar en la presente investigación, la celebración de la Semana Santa en Valladolid durante el siglo XVIII, estuvo marcada por un periodo de cambio sociológico desde planteamientos de pensamientos puramente barrocos, hacia otros plenamente ilustrados, que supusieron un verdadero cambio de mentalidad. La realidad historia vallisoletana no difiere mucho de la realidad nacional y sirve para pulsar las consecuencias que supuso este cambio tanto en la celebración de la Semana Santa, sus cofradías, y sus productos artísticos más destacados, los pasos procesionales. Para tal fin nos hemos valido de fuentes que corren en paralelo a este cambio social desde las crónicas históricas precientíficas 
hasta visiones plenamente ilustradas, ya no solo artísticas, sino lo que nos resulta más atractivo periodísticas. A la par podemos concluir que, si bien este cambio fue traumático para las cofradías penitenciales de la ciudad, sirvió para que surgieran nuevas miradas, ajenas a lo devocional, hacia los pasos, la protección, conservación, restauración y salvaguarda del patrimonio, conceptos plenamente actuales en la actualidad empezaron a fraguarse entonces.

\section{REFERENCIAS}

Agapito y Revilla, J. (1916). Museo Provincial de Bellas Artes de Valladolid. Catálogo de la Sección de Escultura. Valladolid: Imprenta F. Zapatero.

Agapito y Revilla, J. (1925). Las cofradías, las procesiones y los pasos de Semana Santa de Valladolid. Valladolid: Imprenta Castellana.

Almuiña, C. (1996). Manuel Canesi Acebedo y sus coordenadas historiográficas, en Canesi Acevedo, M. (1996). Historia Secular y Eclesiástica de la muy antigua, augusta, coronada, muy ilustre, muy noble, rica y muy leal ciudad de Valladolid. Valladolid: Grupo Pinciano, Caja España y Ayuntamiento de Valladolid.

Alonso Cortes, N. (1933). Introducción a la edición facsímil del Diario Pinciano, en Beristáin, J. M. (1933). Diario Pinciano, Histórico, literario, legal, politico y económico. Primer diario de Valladolid. Valladolid: Imprenta Castellana.

Andres Ordax, S. (1993). Semana Santa en Medina de Rioseco, en Semana Santa en Castillas y León. (pp. 91-103). Valladolid: Junta de Castilla y León y Edilesa.

Anónimo. (1843) Compendio Histórico y descriptivo de Valladolid. Valladolid: Imprenta Julián Pastor

Beristáin, J. M. (1933) Diario Pinciano, Histórico, literario, legal, político y económico. Primer diario de Valladolid. Valladolid: Imprenta Castellana.

Bosarte, I. (1804). Viaje artístico a varios pueblos de España. Con el juicio de las obra de las nobles artes que en ellos existen y épocas a que pertenecen. Viaje a Segovia, Valladolid y Burgos. Madrid: Imprenta Real.

Candeira y Pérez, C. (1945). Guía del Museo Nacional de Escultura de Valladolid. Valladolid: Gráficas Relinguer.

Canesi Acevedo, M. (1996). Historia Secular y Eclesiástica de la muy antigua, augusta, coronada, muy ilustre, muy noble, rica y muy leal ciudad de Valladolid. Valladolid: Grupo Pinciano, Caja España y Ayuntamiento de Valladolid. 
Ceán Bermúdez, J. A. (1800) Diccionario Histórico de los más ilustres profesores de las Bellas Artes en España. Madrid: Viuda de Ibarra, hijos y compañía.

Costas Fontán, N. (2015). Las series de la tercera edad de oro de la ficción televisiva. Cambia la forma de ver televisión. El referente estadounidense: Games of thrones. (Tesis Doctoral). Universidad de Vigo: Pontevedra.

Egido, T. (1983). Introducción a la edición facsímil del Diario de Valladolid, de Ventura Pérez, en Pérez, V. Diario de Valladolid (pp. I-XIV). Valladolid: Editorial Grupo Pinciano.

Egido, T. (1984). La religiosidad colectiva de los vallisoletanos, en Valladolid en el siglo XVIII (pp. 157-260). Valladolid: Ateneo de Valladolid.

Enciso Recio, L. (1984). Valladolid en el Siglo XVIII. Valladolid: Ateneo y Ayuntamiento de Valladolid.

Fernández Del Hoyo, M. A (1983) El Cristo del Perdón obra de Bernardo del Rincón, en Boletín del Seminario de Estudios de arte y Arqueología, 49, 476-481.

Fernández Del Hoyo, M. A (1984). El escultor vallisoletano Francisco Diez de Tudanca (1616-i), en Boletín del Seminario de Estudios de arte y Arqueología, 50, 371388.

Galán, M. (2016). Guía metodológica para diseños de investigación. Recuperado de: http:/ / manuelgalan.blogspot.com/p/guia-metodologica-para-investigacion.html

García Chico, E. (1941). Documentos para el estudio del arte en Castilla. Tomo II. Escultores. Valladolid: Gráficas Afrodísio Aguado.

García Chico, E. (1958). Valladolid. Papeletas de historia y arte. Valladolid: Gráficas Andrés Martín.

García Chico, E. (1962). La Cofradía Penitencial de la Santa Vera Cruz. Valladolid: Gráficas Andrés Martín.

García Chico, E. (1964). Cofradía Penitencial de Nuestra Señora de las Angustias. Valladolid: Sever-Cuesta.

García Vega, B. (1995). Nuestra Señora de la Pasión de Valladolid, en Estudios de Arte en Homenaje al profesor Martín González. (pp. 615-623). Valladolid: Universidad de Valladolid.

González García-Valladolid, C. (1900). Valladolid, Recuerdos y Grandezas. Valladolid: Imprenta de Juan R. Hernando. 
Luna y Moreno, L. \& Fernández González, R. (1986). Gregorio Fernández y la Semana Santa de Valladolid. Valladolid: Sever-Cuesta.

Martí y Monsó, J. (1898-1901). Estudios Histórico Artísticos relacionados principalmente con Valladolid. Valladolid: Leonardo Miñón.

Martín González, J. J. 1974). Juan de Juni. Vida y obra. Madrid: Dirección General de Bellas Artes. Ministerio de Educación y Ciencia.

Martín González, J. J. \& Urrea Fernández, J. (1985). Catalogo Monumental de la provincia de Valladolid. Tomo XIV. Valladolid: Diputación de Valladolid.

Martín González, J. J. (1959). Escultura Barroca Castellana. Tomo I. Madrid: Publicaciones de la Colección Lázaro Galdiano.

Martín González, J. J. (1980). El escultor Gregorio Fernández. Madrid: Dirección General de Bellas Artes. Ministerio de Educación y Ciencia.

Martín González, J. J. (1982). Una plancha de grabado de Nuestra Señora de la Pasión, en Boletín del Seminario de Estudios de arte y Arqueología, 48, 405-408.

Palomino Castro, A. (1986). Vidas. Madrid: Alianza Forma.

Pérez, V. (1885). Diario de Valladolid. Valladolid: Imprenta y Librería Nacional y Extranjera de Hijos de Rodríguez.

Pinheiro Da Veiga, T. (1916). La Fastiginia o Fastos geniales, vida en la corte de Valladolid. Valladolid: Imprenta Colegio de Santiago.

Ponz, A. (1788). Viaje de España. En que se da noticia de los casos más apreciables y dignos de saberse que hay en ella. T. XII. Madrid: Viuda de Ibarra, hijos y compañía.

Prieto Cantero, A. (1983). Historia de la Real Academia de Nobles y Bellas Artes de la Purísima Concepción de Valladolid. Valladolid: Diputación de Valladolid.

Rojo Vega, A. (1999). Fiestas y comedias en Valladolid. Siglos XVI y XVII. Valladolid: Ayuntamiento de Valladolid.

Sánchez Herrero, J. (2003). La Semana Santa de Sevilla. Madrid: Silex.

Sanz, R. (2017). ¿Qué es el método cualitativo? Recuperado de: https://cursos.com/metodo-cualitativo/\#Caracteristicas_del_metodo_cualitativo

Urrea Fernández, J. (1973). El escultor Francisco de Rincón, en Boletín del Seminario de Estudios de arte y Arqueología, 39, 491-500. 
Urrea Fernández, J. (1973). En torno a Gregorio Fernández, en Boletín del Seminario de Estudios de arte y Arqueología, 39, 245-260.

Urrea Fernández, J. (1989). Nuevos datos del escultor Andrés Solanes, en Boletín del Seminario de Estudios de arte y Arqueología, 55, 181-188.

Urrea Fernández, J. (1999). Aproximación biográfica al escultor Gregorio Fernández, en Gregorio Fernández. 1576-1636 (pp. 14-41). Madrid: Fundación BSCH.

Urrea Fernández, J. (2000). Conservación y Exposición de los pasos en el museo, en Pasos Restaurados (pp. 11-24). Valladolid: Museo Nacional de Escultura.

Val, J. D. \& Catalapiedra, F. (1970). Semana Santa de Valladolid. Pasos, cofradías e imagineros. Valladolid: Lex Nova.

Viñaza, Conde de la (1989). Adiciones al Diccionario histórico de los más ilustres profesores de las Bellas Artes de don Juan Agustín Bermúdez. Madrid: Tipografía de Huérfanos.

Wattenberg, F. (1963). Museo Nacional de Escultura de Valladolid. Madrid: Aguilar. S.A.

\section{AUTORES:}

\section{Rubén Sánchez Guzmán}

Licenciado en Historia del Arte por la Universidad Autónoma de Madrid. En la actualidad ejerce como profesor de Historia del Arte y Conocer Madrid, en los Centros Culturales del Ayuntamiento de Madrid. Ha sido docente del I Máster en Escultura Barroca Española. Desde los siglos de oro la sociedad de la información y las redes sociales impartido por la Universidad Internacional de Andalucía y Perito Tasador en Antigüedades y Obras de Arte. Departamento de Arte. Sala de Subastas Lamas Bolaño Madrid. Realizando las funciones de tasación, catalogación y asesoramiento personalizado.

Ruben_sanguzman@hotmail.com

\section{Antonio Rafael Fernández Paradas}

Doctor en Historia del Arte por la Universidad de Málaga, con la tesis doctoral titulada Historiografía y metodologías de la Historia del mueble en España (1872-2011). Un estado de la cuestión. Graduado en Historia del Arte y Licenciado en Documentación por la Universidad de Granada. Máster en Peritaje y Tasación de Antigüedades y obras de arte por la Universidad de Alcalá de Henares. Actualmente es Profesor Ayudante Doctor de la Universidad de Granada, donde imparte docencia en el Departamento de Didáctica de las Ciencias Sociales de la Facultad de Ciencias de la Educación, y docente del Máster Arte y Publicidad de la Universidad de Vigo.

Antonioparadas@ugr.es

Orcid ID: https:// orcid.org/0000-0003-3751-7479 